See discussions, stats, and author profiles for this publication at: https://www.researchgate.net/publication/308519964

\title{
Frequent handling of grazing beef cattle maintained under the rotational stocking method improves temperament over time
}

Article in Animal Production Science · September 2016

DOI: $10.1071 /$ AN16025

\section{CITATIONS}

9

4 authors:

Maria Camila Ceballos

University of Pennsylvania

83 PUBLICATIONS 62 CITATIONS

SEE PROFILE

Aline C Sant'Anna

Federal University of Juiz de Fora

68 PUBLICATIONS 170 CITATIONS

SEE PROFILE

Some of the authors of this publication are also working on these related projects:

130

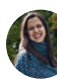

Karen Camille Rocha Góis

University of Pennsylvania

68 PUBLICATIONS 11 CITATIONS

SEE PROFILE

Mateus J R Paranhos da Costa

São Paulo State University

230 PUBLICATIONS 961 CITATIONS

SEE PROFILE

Project Implications of handling reactivity and maternal protective behavior of Ile de France sheep on lambs performance and reactivity View project

Impact of training on good practices of handling on stockpersons attitude, behavior and cattle welfare View project 


\title{
Frequent handling of grazing beef cattle maintained under the rotational stocking method improves temperament over time
}

\author{
Maria C. Ceballos ${ }^{\mathrm{A}, \mathrm{B}}$, Karen Camille R. Góis ${ }^{\mathrm{A}, \mathrm{B}}$, Aline C. Sant'Anna ${ }^{\mathrm{B}, \mathrm{C}}$ \\ and Mateus J. R. Paranhos da Costa ${ }^{\mathrm{B}, \mathrm{D}, \mathrm{E}}$ \\ APrograma de Pós-graduação em Zootecnia, Faculdade de Ciências Agrárias e Veterinárias, \\ Universidade Estadual Paulista, 14.884-900 Jaboticabal, SP, Brazil. \\ ${ }^{B}$ Grupo de Estudos e Pesquisas em Etologia e Ecologia Animal (Grupo ETCO), Departamento de Zootecnia, \\ Faculdade de Ciências Agrárias e Veterinárias, Universidade Estadual Paulista, 14.884-900 Jaboticabal, SP, Brazil. \\ ${ }^{\mathrm{C}}$ Departamento de Zoologia, Instituto de Ciências Biológicas, Universidade Federal de Juiz de Fora, \\ 36.036-330 Juiz de Fora, MG, Brazil. \\ ${ }^{D}$ Conselho Nacional de Desenvolvimento Científico e Tecnológico, Faculdade de Ciências Agrárias e Veterinárias, \\ Universidade Estadual Paulista, 14.884-900 Jaboticabal, SP, Brazil. \\ ${ }^{E}$ Corresponding author. Email: mpcosta@fcav.unesp.br
}

\begin{abstract}
Our aims were to assess the effects of handling frequency on temperament evolution in cattle kept under rotational stocking method (RSM), as well as to compare the temperament of animals maintained under rotational versus alternate stocking (ASM) methods. We evaluated 4256 males raised on pasture from four private properties (Farms 1-4), for a total of 9628 observations. The study was divided into two complementary approaches. In the first one, monthly visits were conducted at 35-day intervals to assess the cattle temperament $(n=1979)$ raised on grazing system using RSM, while, in the second approach, we evaluated the temperament of cattle $(n=3600)$ kept under two different stocking methods, namely, (1) RSM $(n=2007)$, characterised by a high frequency of animal handling and a 4-day grazing period, and (2) ASM $(n=1593)$, characterised by a low frequency of handling and a 20-day grazing period. Composite reactivity score (RS), and flight speed (FS) were considered as temperament indicators. Reductions of RS and FS means were observed during successive assessments under RSM. Significant effects of stocking method on FS $(P<0.05)$ and RS $(P<0.01)$ were found, with lower FS and RS means for animals under RSM than for those under ASM. In conclusion, the frequent handling in the rotational stocking method favoured the improvement of cattle temperament over time, with lower levels of reactivity among cattle raised under this stocking method than with animals raised under the alternate stocking method.
\end{abstract}

Additional keywords: animal behaviour, grazing management, stocking arrangement.

Received 13 January 2016, accepted 5 August 2016, published online 23 September 2016

\section{Introduction}

Deforestation of the Amazon rainforest is a cause for concern worldwide, due to its greenhouse effects and global warming impact (FAO 2006; Malhi et al. 2008; Nepstad et al. 2009). A key factor in Amazon deforestation is the expansion of livestock production (FAO 2006). Therefore, one way of reducing Amazon deforestation is through the rational use of open areas by intensifying cattle production (Nepstad et al. 2009). However, an important public concern is farm-animal welfare, which is negatively affected by the high intensification of production systems, mainly due to overcrowding and low space allowance (de Passillé and Rushen 2005). Therefore, it is necessary to implement sustainable intensification strategies targeting cattle production on pasture, with the potential to increase cattle productivity without impoverishing animal welfare.
Although extensive grazing systems provide more natural environmental conditions for cattle, they involve less frequent human-animal interactions than do intensive systems, making cattle fearful and causing them to express aggressive reactions during handling (Le Neindre et al. 1996). These reactions are often used to characterise cattle temperament (Fordyce et al. 1985; Burrow 1997), which can be broadly defined as the individual behavioural differences that are repeatable over time and across situations, involving reactivity, aggressiveness, willingness to take risks, exploration, sociality and avoidance of novelty, among other traits (Réale et al. 2007). Given the complexity of temperament composition and the challenge of making a practical assessment, for farm animals, temperament has been operationally characterised by the animals' reactivity to handling, which is generally attributed to fear responses 
(Fordyce et al. 1982). The expression of cattle temperament is affected by genetic and environmental factors, including previous experiences with humans. For instance, negative actions by stockpersons during handling cause increased cattle reactivity (Petherick et al. 2009), while positive human-livestock interactions can lead to reduced animal reactivity in future handlings (Becker and Lobato 1997).

The improvement of beef cattle temperament across successive handlings has been evidenced by previous studies (Andrade et al. 2001; Petherick et al. 2002; Fina et al. 2006; Titto et al. 2010), but most of them were conducted with animals kept in feedlot. A few studies have addressed the effects of acclimation to handling on grazing beef cattle temperament, but those studies did not use repeated measurements over time (Cooke et al. 2009a, 2009b, 2012). We found only one longitudinal study addressing this subject, where cattle was kept under an extensive grazing system (Barbosa Silveira et al. 2008).

Moreover, there are no published papers comparing the temperament of cattle kept under different grazing stocking methods. The rotational stocking method (RSM) is considered a promising alternative for the intensification of grazing systems (Perin et al. 2009), as it allows one to combine environmental benefits with improved cattle welfare. The RSM usually involves frequent human-animal interactions during paddock changes. In contrast, the 'alternate' stocking method involves relatively less frequent paddock changes and less human-animal contact. Therefore, the aims of the present study were to assess the effects of handling frequency on temperament evolution in cattle kept under the RSM, as well as to compare the temperament of animals maintained under the rotational veersus alternate stocking methods.

\section{Materials and methods}

This observational study was approved by the Ethics Committee on Animal Use (CEUA) of the Faculty of Agricultural and Veterinary Sciences, Sao Paulo State University, Jaboticabal, SP, Brazil (Protocol numbers 020939/13 and 020938/13).

\section{Animals and management}

The temperament of Nellore and crossed intact males (young bulls) was assessed on four commercial farms located in northeastern Pará state, Brazil (herein referred to as Farms 1-4) where all stockpersons were previously trained in good handling practices, with the aim of promoting cattle welfare.

All animals were kept under a grazing system. Some of them were subjected to RSM, defined as 'a method that utilises recurring periods of grazing and rest among three or more paddocks in a grazing management unit throughout the time when grazing is allowed' (Allen et al. 2011, p. 17), and the rest were kept on an alternate stocking method (ASM), namely 'a method of repeated grazing and resting of forage using two paddocks in succession' (Allen et al. 2011, p. 16). In the present study, the RSM was characterised by frequent cattle handling, with animals being rotated from one paddock to another every 4 days, on average (period of occupation), and $\sim 28$ days of rest (rest period), depending on forage height. The stocking density, defined as 'the relationship between the number of animals and the specific unit of land being grazed at any one time' (Allen et al. 2011, p. 15), was 3 animal units (AU) per hectare. Animals under the RSM were submitted to monthly weighing for stocking-density adjustments. Vaccination and deworming occurred every 6 months, concurrently with weighing. ASM was characterised by less frequent animal handling, and involved moving cattle from one paddock to another every 20 days (on average), according to the height of forage. The stocking density was $\sim 1$ AU per hectare and animals were handled in the corral at 6-month intervals for weighing and sanitary procedures (vaccination and deworming).

The main forage species planted in the paddocks were Brachiaria brizantha cv. Marandú (Farm 1), Panicum maximum cv. Mombasa (Farms 1-3), Brachiaria brizantha cv. Piatã (Farm 2), Cynodon dactylon cv. Tifton (Farm 3), Panicum maximum cv. Tanzania (Farm 3), Brachiaria brizantha cv. Xaraés (Farm 3 and 4) and Panicum maximum cv. Massai (Farm 4).

\section{Study approaches}

The study was divided into two complementary approaches. In the first one, monthly visits were conducted to assess the temperament of cattle raised on RSM, while, in the second approach, we compared the temperament of cattle kept under the two stocking methods, namely RSM and ASM.

\section{Evolution of temperament of cattle kept under grazing system with the RSM}

The evolution of temperament over time for cattle kept under RSM was evaluated in a trial with 1979 intact males from Farms 1-3, as shown in Table 1. Temperament evaluation (EV) sessions were conducted from January to June 2013, 40 days after animals were introduced to that stocking method, and every 35 days, on average, when the animals were driven to the corral for weighing. Data from two EV sessions were used on Farm 1, from three EV sessions on Farm 2, and from four EV sessions on Farm 3.

Table 1. Characteristics of the cattle groups evaluated over time in the rotational stocking method, for each farm

Group, total number of groups; $N$, number of animals; and age, average age of the animals

\begin{tabular}{lcccl}
\hline Farm & Group & $N$ & Age (months) & Breed \\
\hline 1 & 1 & 565 & $20 \pm 1.4$ & Nellore \\
2 & 2 & 220 & $17 \pm 4.2$ & Nellore \\
& 3 & 102 & $26 \pm 6.0$ & Nellore \\
& 4 & 183 & $32 \pm 2.7$ & Nellore \\
& 5 & 253 & $20 \pm 3.0$ & F1 Angus $\times$ Nellore $(n=229)$ \\
& & & & F1 Charolais $\times$ Nellore $(n=24)$ \\
3 & 6 & 180 & $30 \pm 1.6$ & Nellore \\
& 7 & 149 & $11 \pm 1.1$ & F1 Angus $\times$ Nellore \\
& 8 & 198 & $20 \pm 3.7$ & Nellore $(n=175)$ \\
& & & & Crossbred $(n=23)$ \\
& 9 & 129 & $17 \pm 2.8$ & F1 Charolais $\times$ Nellore $(n=82)$ \\
& & & & Crossbred $(n=47)$ \\
& & & &
\end{tabular}


Comparing the temperament of cattle under the RSM versus ASM

We compared the temperament of 2007 young bulls from the RSM with that of 1593 from the ASM (total $n=3600$ ) from Farms 1, 2 and 4, as shown in Table 2. Temperament assessments were conducted once for each animal; for RSM, these were conducted $\sim 150$ days after the animals were introduced to that stocking method. ASM animals had always been kept on this stocking method, and received their evaluation during the same period of the year as did the RSM animals. Some of the RSM animals from Farms 1 and 2 (565 and 758 bulls respectively) were the same in both approaches, but the behavioural observations were not, since the EV session for each approach was conducted on a different day.

\section{Temperament assessment}

Two temperament traits were measured by only one trained observer during handling in the corral, and included the reactivity in the cattle crush (crush test) and the flight speed (FS) test. The crush test (adapted from Fordyce et al. 1985) was performed immediately on the animal's entrance into the cattle crush (during the first $4 \mathrm{~s}$ ), without using restraining devices (head bail and squeeze sides). It consisted of scoring the degree of movement, tension, body posture, breathing, kicking and vocalisations, as described in Table 3 . Then, the scores were added (movement score + tension score + body posture + breathing + kicking + vocalisation), resulting in a single measure of reactivity, namely, the composite reactivity score (RS), which ranged from 6 to 12 . Then, RS was converted to

Table 2. Characteristics of the cattle groups kept under the alternate stocking method (ASM) and the rotational stocking method (RSM) for each farm

$N$, total number of animals; group, number of groups; and age, average age of the animals

\begin{tabular}{|c|c|c|c|c|c|}
\hline Farm & Stocking method & $N$ & Group $(N)$ & Age (months) & Breed \\
\hline \multirow[t]{2}{*}{1} & ASM & 460 & 6 & $26.15 \pm 5.43$ & Nellore \\
\hline & RSM & 567 & 1 & $22.73 \pm 1.42$ & Nellore \\
\hline \multirow[t]{2}{*}{2} & ASM & 559 & 8 & $23.34 \pm 10.46$ & $\begin{array}{l}\text { Nellore }(n=383) \\
\text { F1 Angus } \times \text { Nellore }(n=156) \\
\text { F1 Charolais } \times \text { Nellore }(n=20)\end{array}$ \\
\hline & RSM & 1265 & 4 & $24.77 \pm 6.83$ & $\begin{array}{l}\text { Nellore }(n=885) \\
\text { F1 Charolais } \times \text { Nellore }(n=80) \\
\text { F1 Angus } \times \text { Nellore }(n=300)\end{array}$ \\
\hline \multirow[t]{2}{*}{4} & ASM & 574 & 3 & $22.50 \pm 2.93$ & $\begin{array}{l}\text { Nellore }(n=183) \\
\quad \text { Crossbred European } \times \text { Zebu }(n=391)\end{array}$ \\
\hline & RSM & 175 & 3 & $29.65 \pm 8.69$ & $\begin{array}{l}\text { Crossbred European } \times \text { Zebu }(n=57) \\
\quad \text { Nellore }(n=118)\end{array}$ \\
\hline
\end{tabular}

Table 3. Description of the measurements used to obtain the composite reactivity score (RS)

Adapted from Fordyce et al. (1985)

\begin{tabular}{|c|c|}
\hline Trait & Scale \\
\hline \multirow[t]{4}{*}{ Movement score } & 1 - no movement \\
\hline & 2 - few movements, for less than half of the observation time \\
\hline & 3 - frequent but not vigorous movements, for half of the observation time or more \\
\hline & 5 - constant and vigorous movements, animal jumps and raises its forelimbs off the ground \\
\hline \multirow[t]{3}{*}{ Tension score } & 1 - the animal did not exhibit sudden movements of the tail, head and neck, no muscle tremors, and eye whites were not visible \\
\hline & $\begin{array}{l}2 \text { - the animal exhibited few sudden movements of the tail, head and neck, no muscle tremors, and eye whites } \\
\text { may or may not have been visible }\end{array}$ \\
\hline & 4 - the animal appeared paralysed or 'frozen', muscle tremors were visible \\
\hline \multirow[t]{3}{*}{ Body posture } & 1 - standing, when the animal stands upright with all four feet in contact with the ground, still or moving \\
\hline & 2 - kneeling, when the animal stands on its rear feet but rests on its front knees \\
\hline & 3 - lying, when the ventral part of the animal's body is in contact with the ground \\
\hline \multirow[t]{2}{*}{ Breathing } & 1 - normal, rhythmic and non-audible breathing \\
\hline & 2 - easily audible breathing, or puffing and blowing, but not rhythmic \\
\hline
\end{tabular}


a scale varying from 1 to 7 , where the extremes represented the least and most reactive animals.

The FS test is defined by the speed at which each animal exits a chute (Burrow et al. 1988). It was obtained by recording the time taken by each animal to cover a known distance $(1.35 \mathrm{~m}$ at Farm 1 , $1.36 \mathrm{~m}$ at Farm 2, $2.00 \mathrm{~m}$ at Farm 3 and $1.85 \mathrm{~m}$ at Farm 4) by using a stopwatch; then, the time data (s) were converted to speed $(\mathrm{m} / \mathrm{s})$. Faster animals were considered to be the most reactive (Burrow et al. 1988).

In both stocking methods used in the second approach (RSM and ASM), temperament traits were assessed during handling in the corral, concurrently with weighing (on Farm 4, and in four handling groups on Farm 2) or weighing and vaccination (on Farm 1, and in eigh groups on Farm 2). The crush test was performed before these handling procedures, while the FS test was performed after handling. Thus, the effect of handling procedure was considered in the statistical analysis for Farm 2 for control purposes.

\section{Statistical analyses}

In the present study, the animal was used as the experimental unit. A linear mixed model using the REML method was fitted to assess the evolution of temperament traits over time for cattle maintained on RSM, by using the MIXED procedure with a repeated statement in the SAS software package, version 9.0 (SAS Institute Inc., Cary, NC, USA). The statistical model included $\mathrm{RS}$ and $\mathrm{FS}$ as dependent variables, and the fixed effects were farm (Farms 1-3), temperament evaluation session (EV1 and EV2 at Farm 1; EV1-EV3 at Farm 2 and EV1-EV4 at Farm 3), the farm $\times$ evaluation interaction, and group (farm). The random effect of animal was considered as a repeated measure within the evaluation. We used the Unstructured (UN) variance and covariance of residuals, according to the Bayesian information criterion (BIC).

Spearman's rank correlation coefficients were estimated by using the CORR procedure in SAS, to test the hypothesis that the ranking of animals for each temperament trait (FS and RS) persists over successive evaluations.

To evaluate the effect of stocking method (RSM and ASM) on the temperament traits, a general linear model was fitted using the PROC GLM in SAS. Since the three farms differed in the number of animals, number of groups assessed, group size, breeds, animal category, and type of handling procedures performed in the corral concurrently with the temperament assessment, data were analysed separately for each farm (Farms 1, 2 and 4).
The models included the fixed effects of stocking method (RSM and ASM) and group, and animal age at the time of evaluation was included as a covariate with linear effect. For Farm 2, we also included the fixed effects of breed and handling procedures. The statistical models used are defined in Eqns 1 (for Farms 1 and 3) and 2 (for Farm 2), as follows:

$$
Y_{i j k}=\mu+S M_{i}+G_{\left.j_{(}\right)}+\varepsilon_{\mathrm{ijk}},
$$

where $Y_{i j k}=$ dependent variable (FS and RS), $S M_{i}=$ effect of the $i$ th stocking method ( $i=1$, RSM or $2, \mathrm{ASM}), G_{j(i)}=$ effect of the $j$ th group within $i$ th stocking method and $\varepsilon_{i j k}=$ random error associated with each observation.

$$
Y_{i j k l m}=\mu+S M_{i}+B_{j}+P R O_{k}+G_{l(\mathrm{i})}+\varepsilon_{\mathrm{ijklm}},
$$

where $Y_{i j k}=$ dependent variable (FS and RS), $S M_{i}=$ effect of the $i$ th stocking method ( $i=1, \mathrm{RSM}$ or $2, \mathrm{ASM}), B_{j}=$ effect of the $j$ th breed $(j=1$ : Nellore, 2: Angus $\times$ Nellore, 3: Charolais $\times$ Nellore), $P R O_{k}=$ effect of the $k$ th handling procedure $(k=1$, weighing or 2 , weighing and vaccination), $G_{l(i)}=$ effect of the $l$ th group within $i$ th stocking method and $\varepsilon_{i j k l m}=$ random error associated with each observation.

\section{Results}

Evolution of temperament of cattle kept under grazing system with RSM

For both temperament traits, we observed a significant $(P<0.01)$ farm $\times$ evaluation interaction $\left(\mathrm{FS}: F_{3,6359}=42.79\right.$; and RS: $\left.F_{3,6387}=9.06\right)$ and group (farm) $\left(\mathrm{FS}: F_{6,6359}=60.03\right.$; and RS: $\left.F_{6,6387}=24.53\right)$.

The FS means for Farm 1 and 2 were significantly $(P<0.01)$ different between the first two evaluations, whereas no differences $(P>0.05)$ were observed between the second and third evaluations on Farm 2 (Table 4). Finally, on Farm 3, there were significant $(P<0.01)$ differences among the first three FS means, but not between the third and fourth means $(P>0.05)$ (Table 4). A major reduction between the first two evaluations was observed for Farm 3 (21.59\%), followed by Farms 2 $(13.04 \%)$ and $1(4.11 \%)$. A reduction between the second and third evaluations was observed for Farms $3(13.77 \%)$ and 2 (3.0\%). Finally, for Farm 3, which had a fourth evaluation, we observed a reduction between the third and fourth evaluations (4.20\%). The total percentages of reduction for FS from the first to the last evaluations were $4.11 \%, 15.65 \%$ and $35.23 \%$ for Farms 1, 2 and 3 respectively.

Table 4. Means ( \pm s.e.) of flight speed (FS) and composite reactivity score (RS) for animals kept under the rotational stocking method per farm and for each evaluation conducted (EV)

Means followed by the same lower-case letters in the same row are not statistically different $(P>0.05)$, by Tukey test. Means followed by the same upper-case letters in the same column are not statistically different $(P>0.05)$, by Tukey test

\begin{tabular}{lccccc}
\hline Indicator & Farm & EV 1 & EV 2 & EV 3 & EV 4 \\
\hline FS $(\mathrm{m} / \mathrm{s})$ & 1 & $1.46 \pm 0.02 \mathrm{aB}$ & $1.40 \pm 0.02 \mathrm{bA}$ & - & - \\
& 2 & $1.15 \pm 0.02 \mathrm{aC}$ & $1.00 \pm 0.02 \mathrm{bB}$ & $0.97 \pm 0.02 \mathrm{bB}$ & - \\
& 3 & $1.76 \pm 0.02 \mathrm{aA}$ & $1.38 \pm 0.02 \mathrm{bA}$ & $1.19 \pm 0.02 \mathrm{cA}$ & $1.14 \pm 0.02 \mathrm{c}$ \\
RS & 1 & $3.81 \pm 0.06 \mathrm{aB}$ & $3.36 \pm 0.05 \mathrm{bB}$ & - & - \\
& 2 & $3.04 \pm 0.05 \mathrm{aC}$ & $2.83 \pm 0.04 \mathrm{bC}$ & $2.47 \pm 0.04 \mathrm{cB}$ & - \\
& 3 & $4.20 \pm 0.06 \mathrm{aA}$ & $3.59 \pm 0.05 \mathrm{bA}$ & $3.14 \pm 0.05 \mathrm{cA}$ & $2.86 \pm 0.05 \mathrm{~d}$ \\
\hline
\end{tabular}


We also found significant $(P<0.01)$ reductions for RS on all farms throughout the evaluation sessions (Table 4 ). The largest reduction between the first two evaluations was observed for Farm 3 (14.52\%), followed by Farms 1 (11.81\%) and 2 (6.91\%). Between the second and third evaluations, RS decreased by $12.72 \%$ and $12.53 \%$ for Farms 3 and 2 respectively. Finally, RS decreased by $8.92 \%$ from the third to the fourth evaluation for Farm 3. The total reductions from the first to the last evaluations were $11.81 \%, 18.75 \%$ and $31.90 \%$ for Farms 1,2 and 3 respectively.

On Farm 1, we observed significant $(P<0.01)$ Spearman's rank correlation coefficients between the EV1 and EV2 for FS $\left(r_{\mathrm{s}}=0.70\right)$ and RS $\left(r_{\mathrm{s}}=0.36\right)$. Likewise, for Farms $2(\mathrm{EV} 1-\mathrm{EV} 3)$ and 3 (EV1-EV4), we observed a significant $(P<0.01)$ correlation for both temperament traits, ranging from 0.49 to 0.81 for FS and from 0.24 to 0.39 for RS (Table 5).

\section{Comparing the temperament of cattle under $R S M$ versus $A S M$}

As summarised in Table 6, we observed significant $(P<0.05)$ effects of stocking method and group (stocking method) on FS and RS on all farms assessed. On Farm 2 , breed $(P<0.01)$ and handling procedure $(P<0.05)$ also affected both temperament traits. In general, FS and RS means were significantly lower for RSM than for ASM animals (Table 7).

\section{Discussion}

The present study has offered the first scientific evidence of improved cattle temperament under the RSM, indicating that frequent handling, as part of the RSM, could reduce cattle reactivity over time. This conclusion is based on the lower RS and FS means for animals in the RSM than for those under the ASM, as well as the significant reduction of RS and FS over time in RSM.

Our results corroborated those found in previous reports, which had indicated a general trend for reduction of cattle reactivity over successive assessments, with most of them being performed with cattle kept in feedlots (Fina et al. 2006; King et al. 2006; Barbosa Silveira et al. 2008; Titto et al. 2010), on pasture with supplementation (Barbosa Silveira et al. 2008), or raised on pastures and finished in feedlots (Petherick et al. 2009; Cafe et al. 2011). The authors attributed the reductions in cattle reactivity to the increased frequency of human-cattle interactions during handling routines on the farms (Curley et al. 2006; Fina et al. 2006; Titto et al. 2010), as well as to habituation

Table 5. Spearman's correlation coefficients between flight speed (FS) and composite reactivity score (RS), means for Farms 2 (lower diagonal) and 3 (upper diagonal)

$$
\text { **, } P<0.01
$$

\begin{tabular}{lccccc}
\hline Indicator & Assessment & EV 1 & EV 2 & EV 3 & EV 4 \\
\hline FS & EV 1 & - & $0.65^{* *}$ & $0.65^{* *}$ & $0.62^{* *}$ \\
& EV 2 & $0.71^{* *}$ & - & $0.76^{* *}$ & $0.76^{* *}$ \\
& EV 3 & $0.49^{* *}$ & $0.54^{* *}$ & - & $0.82^{* *}$ \\
RS & EV 1 & - & $0.24^{* *}$ & $0.24^{* *}$ & $0.24 * *$ \\
& EV 2 & $0.36^{* *}$ & - & $0.30^{* *}$ & $0.34^{* *}$ \\
& EV 3 & $0.39^{* *}$ & $0.34^{* *}$ & - & $0.38^{* *}$ \\
\hline
\end{tabular}

(King et al. 2006; Barbosa Silveira et al. 2008; Petherick et al. 2009; Cafe et al. 2011).

A possible explanation for the improvement of cattle temperament over time is the increased contact of RSM animals with the handlers, both in the corral and pastures (during paddock rotation). These frequent and usually neutral or positive forms of contact probably promoted animal habituation and associative learning (especially operant conditioning with positive reinforcement). Habituation is a learning process involving reduced responses to monotonous and repeated stimulation (Sato 1995), and associative learning operant conditioning with positive reinforcement occurs when 'a subject is rewarded after engaging in operant behaviour of a selected kind' (Spielberger and Douglas 1966, p. 1). The animals in our study could be habituated to the repeated handling in the corral (as they were weighed every month), and could also be subject to operant conditioning, by receiving positive

Table 6. Analysis of variance summary of composite reactivity score (RS) and flight speed (FS) for each farm

\begin{tabular}{|c|c|c|c|c|c|}
\hline Indicator & Farm & Source of variation & d.f. & $F$ & $P$-value \\
\hline \multirow{11}{*}{ FS } & \multirow[t]{3}{*}{1} & Stocking method & 1 & 12.34 & $<0.01$ \\
\hline & & Group (stocking method) & 5 & 8.10 & $<0.01$ \\
\hline & & Error & 1017 & & \\
\hline & \multirow[t]{5}{*}{2} & Stocking method & 1 & 35.06 & $<0.01$ \\
\hline & & Breed & 2 & 6.59 & $<0.01$ \\
\hline & & Handling procedure & 1 & 23.76 & $<0.01$ \\
\hline & & Group (stocking method) & 10 & 5.44 & $<0.01$ \\
\hline & & Error & 1789 & & \\
\hline & \multirow[t]{3}{*}{4} & Stocking method & 1 & 4.42 & $<0.05$ \\
\hline & & Group (stocking method) & 4 & 22.61 & $<0.01$ \\
\hline & & Error & 743 & & \\
\hline \multirow[t]{11}{*}{ RS } & \multirow[t]{3}{*}{1} & Stocking method & 1 & 39.13 & $<0.01$ \\
\hline & & Group (stocking method) & 5 & 3.23 & $<0.01$ \\
\hline & & Error & 1018 & & \\
\hline & \multirow[t]{5}{*}{2} & Stocking method & 1 & 65.79 & $<0.01$ \\
\hline & & Breed & 2 & 11.69 & $<0.01$ \\
\hline & & Handling procedure & 1 & 5.19 & $<0.05$ \\
\hline & & Group (stocking method) & 10 & 2.50 & $<0.01$ \\
\hline & & Error & 1797 & & \\
\hline & \multirow[t]{3}{*}{4} & Stocking method & 1 & 49.22 & $<0.01$ \\
\hline & & Group (stocking method) & 4 & 12.43 & $<0.01$ \\
\hline & & Error & 742 & & \\
\hline
\end{tabular}

Table 7. Comparison of flight speed (FS) and composite reactivity score (RS) for the different stocking methods, rotational stoking method (RSM) and alternate stocking method (ASM), for each farm Means $( \pm$ s.d.) and maximum and minimum values of FS $(\mathrm{m} / \mathrm{s})$ and RS (scores from 1 to 7 ). ${ }^{* *}, P<0.01 ; *, P<0.05$

\begin{tabular}{lcll}
\hline Indicator & Farm & \multicolumn{1}{c}{ RSM (min.-max.) } & \multicolumn{1}{c}{ ASM (min.-max.) } \\
\hline FS & 1 & $1.86 \pm 0.76(0.41-4.49)$ & $2.15 \pm 0.92(0.22-4.49)^{* *}$ \\
& 2 & $1.23 \pm 0.62(0.11-3.89)$ & $1.45 \pm 0.80(0.20-4.00)^{* *}$ \\
\multirow{2}{*}{ RS } & 4 & $1.07 \pm 0.52(0.23-2.53)$ & $1.17 \pm 0.58(0.14-3.56)^{*}$ \\
& 1 & $2.67 \pm 1.27(1-7)$ & $3.49 \pm 1.37(1-7)^{* *}$ \\
& 2 & $2.65 \pm 1.29(1-6)$ & $3.32 \pm 1.31(1-7)^{* *}$ \\
& 4 & $2.77 \pm 1.32(1-6)$ & $3.51 \pm 1.19(1-7)^{* *}$ \\
\hline
\end{tabular}


reinforcement when offered better-quality and more abundant pasture every time the paddocks were changed. As described in previous studies, the food supply has also been associated with reducing animal fear towards humans (Boivin et al. 1992; Jago et al. 1999). These learning processes could have contributed to a reduction of animals' fear towards humans, thus reducing their reactivity over time.

The differences in the reduction of FS and RS among farms suggests that there are characteristics inherent to each farm that can influence cattle behaviour. For example, Farm 3 showed the greatest reduction in FS $(21.59 \%)$ and RS $(14.52 \%)$ from the first to the second evaluations, compared with Farm 1 (FS = $4.11 \%$ and $\mathrm{RS}=11.81 \%)$ and Farm $2(\mathrm{FS}=13.04 \%$ and $\mathrm{RS}=$ $6.91 \%$ ). This is probably because Farm 3 animals showed the highest FS and RS values at the first evaluation. Some factors that could influence the magnitude of this reduction were controlled by the statistical models used in the study, such as differences in group size, age and animal breed. However, other variables we did not have access to, i.e. characteristics intrinsic to each farm, such as stockpersons' attitudes (Hemsworth et al. 2000; Boivin et al. 2007), and animals' previous experiences (Petherick et al. 2009), were not included in the analysis, and may have had an impact on the variations of FS and RS across farms.

For FS, the ranking of animals remained more stable over successive assessments, as evidenced by the moderate to high Spearman's rank correlation coefficients. For RS, the low correlation coefficients between assessments indicated weak consistency in the ranking of animals over time. These results are similar to those shown in studies by Cafe et al. (2011), who found moderate to low correlations (from 0.18 to 0.44 ) between repeated measures of chute score over eight successive assessments, and higher correlation values (from 0.33 to 0.75 ) between FS measures over time. Furthermore, previous studies comparing the degree of repeatability for different indicators of temperament have shown FS to be more repeatable than RS in the squeeze chute (Turner et al. 2011; MacKay et al. 2013), also indicating a greater consistency over time for FS.

These results may be attributed to the quantitative and objective nature of the FS measure, which generates a continuous variable (Burrow and Corbet 2000; Sant'Anna et al. 2013) that does not depend on the observer perception, ability or training for its measurement (Sant'Anna et al. 2013). According to Sebastian et al. (2011), the objectivity of measures such as FS makes them better candidates for temperatment assessment in genetic selection and ethological studies. However, it should be noted that FS also has methodological limitations, as it does not identify animals that display a 'freezing' reaction. Animals in freezing could be extremely frightened and physiologically stressed, but the FS is not sensitive enough to identify them due to their slow speed (M. C. Ceballos, pers. obs.). A visual score such as RS can be used to assess these reactions in the animals as they enter the chute (Sant'Anna et al. 2013). Therefore, it is very important to use more than one indicator for temperament assessment, as no single test is sensitive enough to identify an animal's multiple temperament characteristics (Manteca and Deag 1993).

It is noteworthy that most cattle assessed in the evolution of temperament approach were adults or were close to adulthood (over 20 months of age), reinforcing the hypothesis that the observed temperament improvement was due to the frequent handling in the pasture and corral, and not to animals' maturity. At younger ages (below 18 months of age), animals could still be in the process of temperament determination (Kerr and Wood-Gush 1987), and temperament traits are expected to become increasingly stable as cattle become older (Grandin and Deesing 1998). In general, our results corroborated previous reports addressing the effects of successive handling on cattle temperament, showing that the adoption of the RSM substantially reduces reactivity in adult cattle over time.

\section{Conclusions}

We conclude that the rotational stocking method improves cattle temperament over time, resulting in less reactive animals than those kept in an alternate stocking method. Our conclusions are supported by the high frequency of neutral and positive human-cattle interactions over time after the adoption of the rotational stocking method. Although both temperament traits presented significant mean reductions over time, animal ranking by FS was relatively more stable than that by RS.

Concerns about Amazon deforestation require the adoption of alternative strategies to promote the sustainable intensification of cattle production on pasture. These strategies must take into account handling practices and focus on promoting human and animal welfare on farms. Our findings indicated that the implementation of RSM to intensify cattle production on pasture has the potential to meet such demands, improving human-animal relationship, facilitating handling procedures and reducing the risks of labour accidents. These benefits, combined with the well known increment in cattle productivity, can be used as powerful arguments to convince farmers to increase profitability without opening new areas in the Amazon forest.

\section{Acknowledgements}

We thank the farms that participated in this study (Marupiara, Santa Maria, São Luiz and Joaíma farms). This research was funded by Fundo Vale Pecuária Verde Project. The study was part of the Master's thesis of the manuscript's lead and second authors in the Graduate Program in Animal Science at São Paulo State University (UNESP), Jaboticabal Campus, Brazil.

\section{References}

Allen VG, Batello C, Berretta EJ, Hodgson J, Kothmann M, Li X, Mclvor J, Milne J, Morris C, Peeters A, Sanderson M (2011) An international terminology for grazing lands and grazing animals. Grass and Forage Science 66, 2-28. doi:10.1111/j.1365-2494.2010.00780.x

Andrade O, Orihuela A, Solano J, Galina CS (2001) Some effects of repeated handling and the use of a mask on stress responses in zebu cattle during restraint. Applied Animal Behaviour Science 71, 175-181. doi:10.1016/ S0168-1591(00)00177-5

Barbosa Silveira ID, Fischer V, Wiegand MM (2008) Temperamento em bovinos de corte: métodos de medida em diferentes sistemas produtivos. Archivos de Zootecia 57, 321-332.

Becker BG, Lobato JFP (1997) Effect of gentle handling on the reactivity of zebu crossed calves to humans. Applied Animal Behaviour Science 53, 219-224. doi:10.1016/S0168-1591(96)01091-X

Boivin X, Le Neidre P, Chupin JM (1992) Establishment of cattle-human relationships. Applied Animal Behaviour Science 32, 325-335. doi:10.1016/S0168-1591(05)80025-5 
Boivin X, Marcantognini L, Boulesteix P, Godet J, Brulé A, Veissier I (2007) Attitudes of farmers towards Limousin cattle and their handling. Animal Welfare 16, 147-151.

Burrow HM (1997) Measurements of temperament and their relationships with performance traits of beef cattle. Animal Breeding Abstracts 65, 477-495.

Burrow HM, Corbet NJ (2000) Genetic and environmental factors affecting temperament of zebu and zebu-derived beef cattle grazed at pasture in the tropics. Australian Journal of Agricultural Research 51, 155-162. doi:10.1071/AR99053

Burrow HM, Seifert GW, Corbet NJ (1988) A new technique for measuring temperament in cattle. Proceedings of the Australian Society of Animal Production 17, 154-157.

Cafe LM, Robinson DL, Ferguson DM, Mcintyre BL, Geesink GH, Greenwood PL (2011) Cattle temperament: persistence of assessments and associations with productivity, efficiency, carcass and meat quality traits. Journal of Animal Science 89, 1452-1465. doi:10.2527/jas.20103304

Cooke RF, Arthington JD, Araujo DB, Lamb GC (2009a) Effects of acclimation to human interaction on performance, temperament, physiological responses, and pregnancy rates of Brahman-crossbred cows. Journal of Animal Science 87, 4125-4132. doi:10.2527/jas. 2009-2021

Cooke RF, Arthington JD, Austin BR, Yelich JV (2009b) Effects of acclimation to handling on performance, reproductive, and physiological responses of Brahman-crossbred heifers. Journal of Animal Science 87, 3403-3412. doi:10.2527/jas.2009-1910

Cooke RF, Bohnert DW, Cappellozza BI, Mueller CJ, Delcurto T (2012) Effects of temperament and acclimation to handling on reproductive performance of Bos taurus beef females. Journal of Animal Science 90, 3547-3555. doi:10.2527/jas.2011-4768

Curley KO Jr, Paschal JC, Welsh TH Jr, Randel RD (2006) Technical note: exit velocity as a measure of cattle temperament is repeatable and associated with serum concentration of cortisol in Brahman bulls. Journal of Animal Science 84, 3100-3103. doi:10.2527/jas.2006-055

de Passillé AM, Rushen J (2005) Food safety and environmental issues in animal welfare. Scientific and Technical Review of the Office International des Epizooties 24, 757-766. doi:10.20506/rst.24.2.1599

FAO (Food and Agriculture Organization of the United Nations) (2006) 'Livestock's long shadow: environmental issues and options.' (FAO: Rome)

Fina M, Casellas J, Manteca X, Piedrafita J (2006) Analysis of temperament development during the fattening period in the semi-feral bovine calves of the Alberes Massif. Animal Research 55, 389-395. doi:10.1051/ animres: 2006030

Fordyce G, Goddard ME, Seifert GW (1982) The measurement of temperament in cattle and the effect of experience and genotype. Proceedings of the Australian Society of Animal Production 14, 329-332.

Fordyce G, Goddard ME, Tyler R, Williams G, Toleman MA (1985) Temperament and bruising of Bos indicus cross cattle. Australian Journal of Experimental Agriculture 25, 283-288. doi:10.1071/ EA9850283

Grandin T, Deesing D (1998) Genetics and behavior during handling, restraint, and herding. In 'Genetics and the behavior of domestic animals’. (Eds T Grandin, D Deesing) pp. 319-341. (Academic Press: San Diego, CA)

Hemsworth PH, Coleman GJ, Barnett JL, Borg S (2000) Relationships between human-animal interactions and productivity of commercial dairy cows. Journal of Animal Science 78, 2821-2831. doi:10.2527/ $2000.78112821 \mathrm{x}$

Jago JG, Krohn CC, Matthews LR (1999) The influence of feeding and handling on the development of the human-animal interactions in young cattle. Applied Animal Behaviour Science 62, 137-151. doi:10.1016/ S0168-1591(98)00219-6
Kerr SGC, Wood-Gush DGM (1987) The development of behaviour patterns and temperament in dairy heifers. Behavioural Processes 15, 1-16. doi:10.1016/0376-6357(87)90029-5

King DA, Schuehle Pfeiffer CE, Randel RD, Welsh TH Jr, Oliphint RA, Baird BE, Curley KO Jr, Vann RC, Hale DS, Savell JW (2006) Influence of animal temperament and stress responsiveness on the carcass quality and beef tenderness of feedlot cattle. Meat Science 74, 546-556. doi:10.1016/j.meatsci.2006.05.004

Le Neindre P, Boivin X, Boissy A (1996) Handling of extensively kept animals. Applied Animal Behaviour Science 49, 73-81. doi:10.1016/ 0168-1591(95)00669-9

MacKay JRD, Turner SP, Hyslop J, Deag JM, Haskell MJ (2013) Short-term temperament tests in beef cattle relate to long-term measures of behavior recorded in the home pen. Journal of Animal Science 91, 4917-4924. doi:10.2527/jas.2012-5473

Malhi Y, Roberts JT, Betts RA, Killeen TJ, Li W, Nobre CA (2008) Climate change, deforestation, and the fate of the Amazon. Science 319, 169-172. doi:10.1126/science.1146961

Manteca X, Deag JM (1993) Individual differences in temperament of domestic animals: a review of methodology. Animal Welfare 2, 247-268.

Nepstad D, Soares-Filho BS, Merry F, Lima A, Moutinho P, Carter J, Bowman M, Cattaneo A, Rodrigues H, Schwartzman S, McGrath DG, Stickler CM, Lubowski R, Piris-Cabezas P, Rivero S, Alencar A, Almeida O, Stella O (2009) The end of deforestation in the Brazilian Amazon. Science 326, 1350-1351. doi:10.1126/science.1182108

Perin R, Martins GC, Muniz SR, Linhares GM (2009) Sistema de pastejo rotacionado intensivo como alternativa para a recuperação de áreas degradadas no Estado do Amazonas. Amazônia Ciência e Desenvolvimento 4, 235-243.

Petherick JC, Holroyd RG, Doogan VJ, Venus BK (2002) Productivity, carcass and meat quality of lot-fed Bos indicus cross steers grouped according to temperament. Australian Journal of Experimental Agriculture 42, 389-398. doi:10.1071/EA01084

Petherick JC, Doogan VJ, Holroyd RG, Olsson P, Venus BK (2009) Quality of handling and holding yard environment, and beef cattle temperament: 1. Relationships with flight speed and fear of humans. Applied Animal Behaviour Science 120, 18-27. doi:10.1016/j.applanim.2009.05.008

Réale D, Reader SM, Sol D, McDougall PT, Dingemanse NJ (2007) Integrating animal temperament within ecology and evolution. Biological Reviews of the Cambridge Philosophical Society 82, 291-318. doi:10.1111/j.1469-185X.2007.00010.x

Sant'Anna AC, Paranhos da Costa MJR, Baldi F, Albuquerque LG (2013) Genetic variability for temperament indicators of Nellore cattle. Journal of Animal Science 91, 3532-3537. doi:10.2527/jas.2012-5979

Sato T (1995) Habituação e sensibilização comportamental. Psicologia USP 6, 231-276.

Sebastian T, Watts J, Stookey J, Buchanan F, Waldner C (2011) Temperament in beef cattle: methods of measurement and their relationship to production. Canadian Journal of Animal Science 91, 557-565. doi:10.4141/cjas2010-041

Spielberger CD, Douglas L (1966) Descriptive behaviorism versus cognitive theory in verbal operant conditioning. Psychological Review 73, 306-326. doi:10.1037/h0023454

Titto EAL, Titto CG, Gatto EG, Silva NCM, Mourão GB, Nogueira Filho JCM, Pereira AMF (2010) Reactivity of Nellore steers in two feedlot housing systems and its relationship with plasmatic cortisol. Livestock Science 129, 146-150. doi:10.1016/j.livsci.2010.01.017

Turner SP, Navajas EA, Hyslop JJ, Ross DW, Richardson RI, Prieto N, Bell M, Jack MC, Roehe R (2011) Associations between response to handling and growth and meat quality in frequently handled Bos taurus beef cattle. Journal of Animal Science 89, 4239-4248. doi:10.2527/ jas.2010-3790 